\title{
Voltage control of switched reluctance generator using grasshopper optimization algorithm
}

\author{
M. Bahy ${ }^{1}$, Adel S. Nada ${ }^{2}$, S. H. Elbanna ${ }^{3}$, M. A. Morsy Shanab ${ }^{4}$ \\ ${ }^{1,4}$ Electrical Power and Machine Department, the Higher Institute of Engineering at El-Shorouk City, Egypt. \\ ${ }^{2,3}$ Electrical Power and Machine Department, AL-Azhar University, Egypt.
}

\begin{tabular}{l}
\hline Article Info \\
\hline Article history: \\
Received Apr 18, 2019 \\
Revised Aug 1, 2019 \\
Accepted Nov 16, 2019 \\
\hline
\end{tabular}

Keywords:

Grasshopper optimization algorithm

Particle swarm optimization PI controller

Switched reluctance generator Whale optimization algorithm

\begin{abstract}
This paper introduces a terminal voltage control approach of a Switched Reluctance Generator (SRG) based wind turbine generating systems. The control process is employed using a closed loop stimulated by the error between the reference voltage and the generator output voltage due to load and wind speed variation. This error feeds the tuned Proportional Integral controller (PI). The tuning by conventional analytical methods of the PI controller is difficult due to substantial non-linearity. A new strategy approach for evaluating optimum PI controller parameters of voltage control of SRG using the Grasshopper Optimization Algorithm (GOA) is addressed here. This approach is a simple and effective algorithm, capable of solving numerous optimization issues. The simple algorithm ensures that the optimum PI controller parameters are optimized with great quality. The performance of the proposed GOA-PI controller is achieved by using the integral of time weighted squared error (ITSE). The effectiveness of the proposed strategy is tested with the three-phase 12/8 structure SRG. Outcomes indicate the supremacy of GOA over Whale Optimization Algorithm (WOA) and Particle Swarm Optimization (PSO) in terms of control performance measures.
\end{abstract}

This is an open access article under the CC BY-SA license.

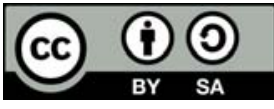

\section{Corresponding Author:}

M. Bahy,

Department of Power and Electrical Machine Engineering,

The Higher Institute of Engineering at El-Shorouk City,

4J94+QF El Shorouk City, Al Shorouk, Cairo, Egypt.

Email: eng.mohamedbahy@gmail.com

\section{INTRODUCTION}

The Switched Reluctance Generator (SRG) offers several advantages over other generators types, like high power density, mechanical robustness, no windings and permanent magnets on the rotor, high efficiency, performance in a broad range of speeds, low manufacturing costs, and high fault tolerance [1-3]. This type of machine is viable for many applications with variable speed demands in harsh environments, as in the field of wind power generation, aircraft power systems, battery charging and electrical traction $[4,5]$.

Energies were used to adjust the SRG to low and medium speeds in wind applications, reducing the total cost to eliminating the gearbox. Some techniques have been suggested in modern studies to avoid the effects of load and speed variation of the voltage generation for SRG systems [6, 7]. Several controllers have been introduced for SRG to achieve better dynamic performance. Examples for these controllers are Proportional Integral (PI) control which is simple in realization to be employed in SRG control [7, 8].

PI controller is widely implemented in the production process as the control strategy. Basically, the system response, steady-state error, and the system stability will be improved by PI controller. Moreover, the 
PI parameters are dependent on the system features. Therefore, the proper or optimum PI parameters are necessary to achieve the desired performance. Traditional and intelligent adjustments are methods of tuning PI parameters. Ziegler and Nichols suggested the conventional PI adaptation to the formula based on observation of the sensitivity, amplitude, and natural frequency of systems [9].

For these purposes, increasing the capabilities of PI controllers by adding new features is highly desirable. Particle Swarm Optimization (PSO), Artificial Bee Colony (ABC), Differential Evolution (DE), Teaching Learning Based Optimization (TLBO), Gravitational Search Algorithm (GSA), Bat Algorithm (BA), Pattern Search Algorithm (PSA), Firefly Algorithm (FA), Bio-Geography Based Optimization (BBO), Ant Colony Optimization (ACO), Cuckoo Search (CS) Algorithm, Whale Optimization Algorithm (WOA), Imperialist Competitive Algorithm (ICA) and Genetic Algorithm (GA) are the methods of tuning based on heuristic optimization to improve the efficiency of the mentioned controller types. [10, 11].

Grasshopper Optimization Algorithm (GOA) is Saremi's population-based single objective stochastic and heuristic optimization technique [12], which emulates Grasshopper's behavior in nature, and mathematically models it to solve problems of optimization with contentious variables. Tests were conducted with different test functions such as unimodal, multimodal, composite and CEC2005, and real structural design problems, show that GOA can efficiently resolve many problems of optimization (also those with unknown search areas) [12]. As GOA considers a certain problem of optimization as a black-box and doesn't need gradient information from the search area, this enables it a highly appropriate optimization technique in different areas for any correctly formulated optimization problem [10].

Since the nonlinear nature and/or magnitude of a problem does not affect the GOA and WOA, Where early convergence usually shows certain global optimization strategies, the best solution is found with faster convergence more efficiently. In this study, taking into account these advantages of the GOA algorithm, a GOA-based PI (GOA-PI) controllers proposed for SRG voltage control. It should be noted that no such analysis has been suggested before in the literature. Some comparative results between the proposed GOA-PI controller and both WOA-PI and PSO-PI controllers will be presented in order to confirm the robustness and effectiveness of the proposed method.

This paper introduces the development procedures of GOA-based PI controllers, WOA and PSO optimization techniques. The task of that controller is to generate the turn off angle ( $\theta$ off) of the magnetization stage of SRG to regulate the generated voltage under different operating conditions, such as load and wind speed variations.

\section{OPERATION OF THREE-PHASE SWITCHED RELUCTANCE GENERATOR}

A SRG is a machine that a doubly salient pole supplied by unipolar power converters. The configuration of a 3 -phase machine with 12 poles on the stator and 8 poles on the rotor is displayed in Figure 1(a). The asymmetric half-bridge converter (AHB) for a three-phase SRG shown in Figure 1 (b), mainly because it enables the machine to be driven both as a generator and as a motor.

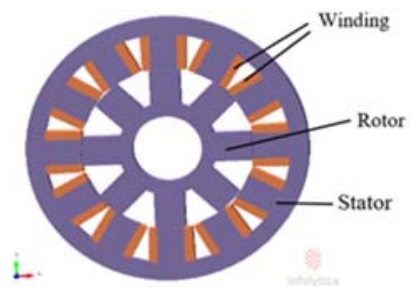

(a)

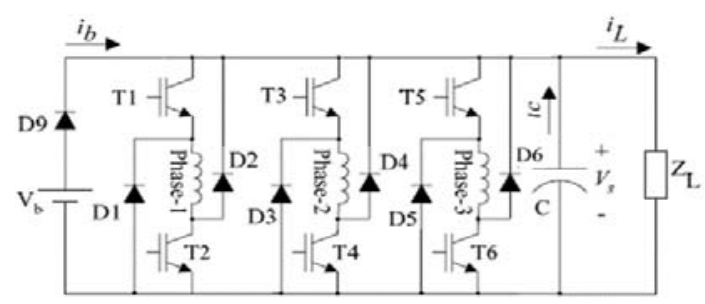

(b)

Figure 1. (a) Machine structure, (b) Asymmetric half bridge converter for a 3-ph SRG

The windings of the stator are of a concentrated type and simple shape, the rotor has no winding, no magnets and low inertia [3,13]. The characteristics of the SRG depend on numerous features, mainly: machine structure (number of phases, number of stator and rotor poles, stator and rotor arcs), magnetization characteristic of the laminations, configuration of the converter and methodology of controller [13, 14]. Concentrated stator windings are divided into four diametrically symmetrical pairs linked in series to form

Int J Pow Elec \& Dri Syst Vol. 11, No. 1, Mar 2020 : 75 - 85 
phases. Due to The variation in the air gap and non-linear iron magnetization, the machine flux linkage is a nonlinear function of the stator current and the angular position of the rotor as in

$$
\psi=\psi\left(i_{s}, \theta\right)
$$

Where $\psi$ is the flux linked by the winding, $i_{s}$ is the phase current and $\theta$ is the position of the rotor related to the aligned position $\left(\theta=0^{\circ}\right)$.

By the use the finite-element field calculation such as MotorSolve software with defined parameters, this complex feature can be realized [15]. The SRM characteristic of magnetization considered in the present paper is illustrated in Figure 2(a). The characteristic of magnetization comprises is a family of curves signifying the machine flux linkage as a function of current of the phase for various rotor positions from aligned position $\left(\theta=0^{\circ}\right)$ to unaligned position $\left(\theta=22.5^{\circ}\right)$. The area under the curve is the co-energy magnetic field $W_{c}$, which the relationship could be described,

$$
W_{c}=\int_{0}^{i_{s}} \psi\left(\theta, i_{s}\right) d i
$$

The electromagnetic torque $T$ is proportional to the change of the machine's magnetic co-energy $W_{c}$ at every phase of the SRM, while the machine rotates:

$$
T=\frac{\partial W_{c}}{\partial \theta} i_{S}=\text { constant }
$$

Where $\mathrm{L}$, is the unsaturated phase inductance, then the flux $\psi$ will be:

$$
\psi=L(\theta) \cdot i_{s}
$$

Then the familiar simplified relationship for SRM torque T is [16]

$$
T=\frac{1}{2} i_{S}{ }^{2} \frac{d L(\theta)}{d \theta}
$$

Where $\frac{d L}{d \theta}$ is positive for motoring and negative for generating modes as shown in Figure 2(b). By injecting current into phase windings during the period when the developed torque is negative, electrical energy can be generated as $\theta$ changes from 0 to $22.5^{\circ}$ as illustrated in Figure 2(b).

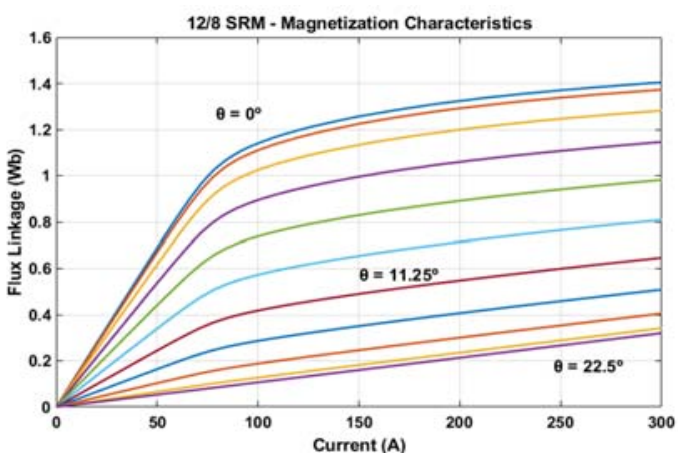

(a) Magnetization curves

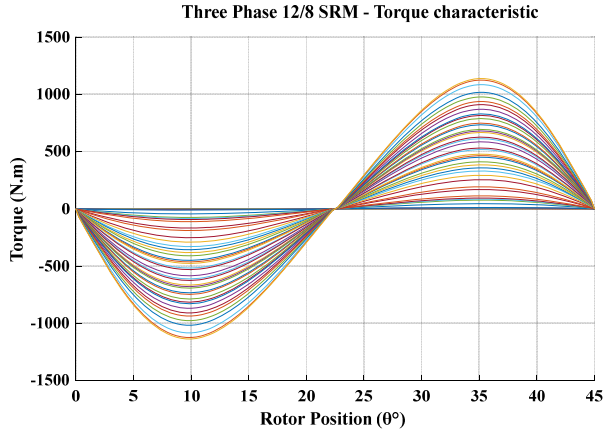

(b) Torque profile

Figure 2. Magnetization and torque profile of $12 / 8 \mathrm{SRG}$

\section{MATHEMATICAL MODEL OF THE SRG}

A MATLAB/SIMULINK tools are used to represent the nonlinear model of $12 / 8 \mathrm{SRG}$. The SRG is a non-linear electrical system accompanied by a mechanical system which displays the mechanical dynamics 
of the generator. A single phase terminal voltage $V$ of SRG is linked to the flux linked of the winding as seen below [16]

$$
V=i_{S} R_{S}+\frac{d \psi}{d t}
$$

where, $R_{s}$ is the resistance of the stator. The magnetic flux linkage with the windings is deliberated by.

$$
\psi(t)=\int_{0}^{t}\left(V-i_{s} R_{S}\right) d t
$$

The currents formed by the nonlinear function $i_{S}(\psi, \theta)$, are presented as a lookup table ITBL. The nonlinear function $T_{e}\left(i_{s}, \theta\right)$, which is also used as a TTBL look-up table provides for the electromagnetic torques created by the stator phases. The two lookup tables ITBL and TTBL used in modeling of the SRG are illustrated in Figure 3.

$$
T_{e}=\sum_{j=1}^{N_{s}} T_{j}\left(\theta, i_{s}\right)
$$

Where $T_{e}$ is the electrical torque and $j$ is the number of phases of SRG. The resulting torque equation for the SRG can be represented as:

$$
T_{e}=T_{m}+J \frac{d \omega}{d t}+B \omega
$$

Where $T_{m}$ is the prime mover torque, $J$ is the inertia of the rotor, and $B$ is the coefficient of friction. The summation of electric output power of each phase in one electric cycle $P_{\text {out }}$ is the average power of SRG phases

$$
P_{\text {out }}=\frac{1}{T} \sum_{j=1}^{N_{S}} \int_{0}^{T} v_{j} i_{s j} d t
$$

Where $T, N s, V_{j}$ and $i_{s j}$ are the conduction period of one phase, the number of motor phases, voltage and current of Phase $j$.

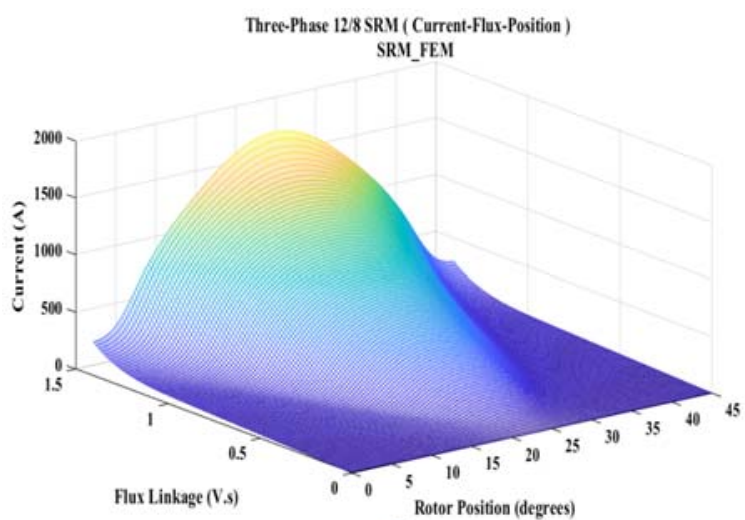

(a) Current versus rotor position and flux.

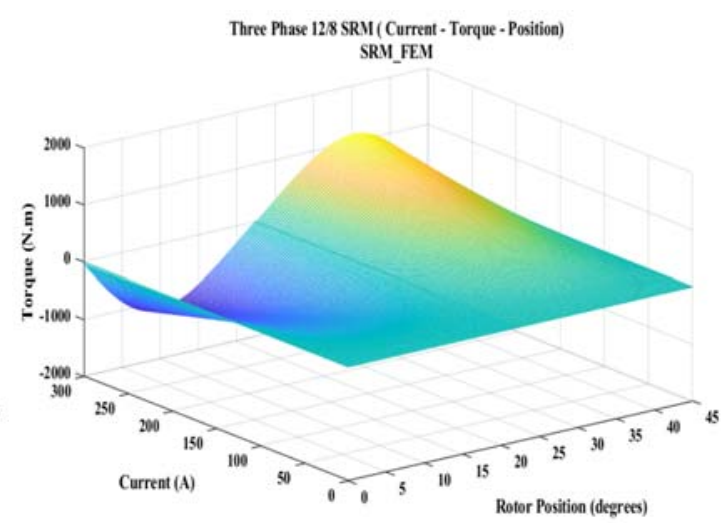

(b) Torque versus rotor position and current.

Figure 3. SRG Lookup tables ITBL and TTBL

\section{PERFORMANCE STUDY OF SRG}

A SIMULINK diagram that used to determine the generator performance is shown in the Figure 4. A three-phase asymmetric power converter supplies the SRG. With this structure, the currents of the phases can be controlled independently. To implement turn-on and turn-off angles of each phase perfectly, a rotor position sensor is used. To calculate the different variables of the system and mark the measurements, 
measuring devices and signal processing blocks are applied to the system. Table 1 provides the SRG parameters used in this paper.

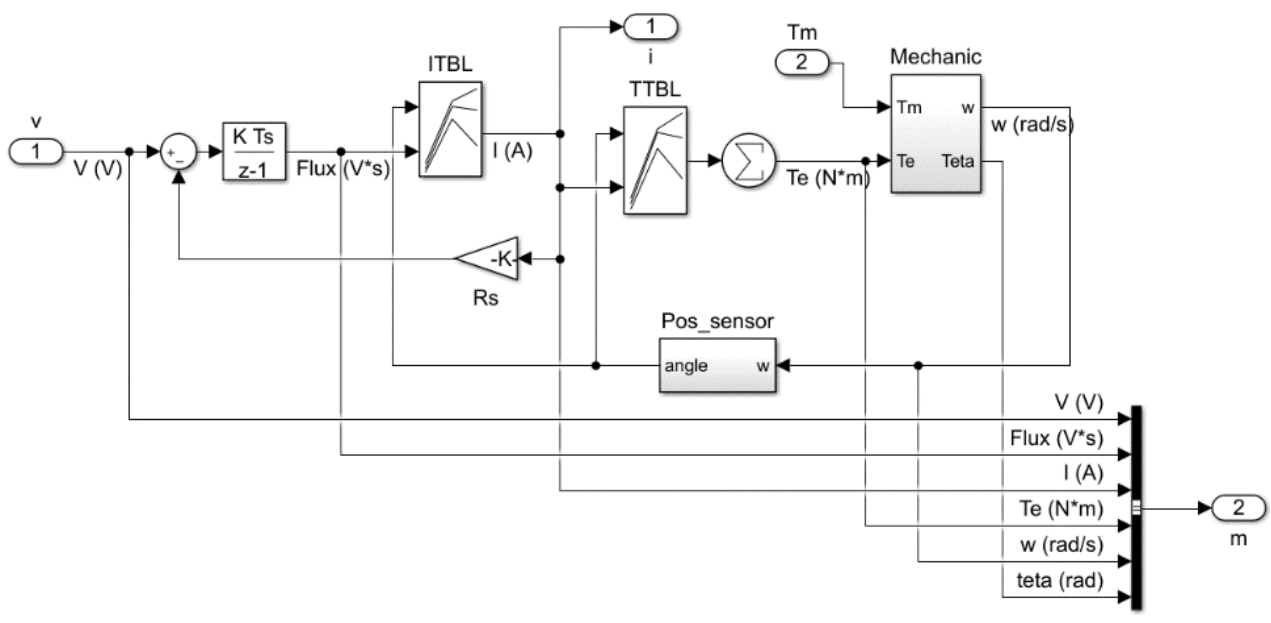

Figure 4. Diagram of the simulink for the $12 / 8 \mathrm{SRG}$

Figure 5 shows waveforms of the flux, current, voltage and torque waveforms for turn-on and turnoff angles $\left(\alpha=-7^{\circ}, \beta=9.5^{\circ}\right)$. The main simulation results obtained for wind speed $12(\mathrm{~m} / \mathrm{s})$ or $\mathrm{N}=1000 \mathrm{rpm}$.

Table 1. SRG

\begin{tabular}{ll}
\hline Parameter & SRG \\
\hline Voltage $(\mathrm{V})$ & 600 \\
Torque $(\mathrm{N} . \mathrm{m})$ & 650 \\
Output Power $(\mathrm{kW})$ & 100 \\
Stator poles & 12 \\
Rotor poles & 8 \\
Base speed $\left(\mathrm{r} . \mathrm{min}^{-1}\right)$ & 1200 \\
Resistance $/$ hhase $(\Omega)$ & 0.03109 \\
Moment of inertia/(kg.m $\left.{ }^{2}\right)$ & 0.05 \\
Friction coefficient/(N.m.s) & 0.02 \\
\hline
\end{tabular}
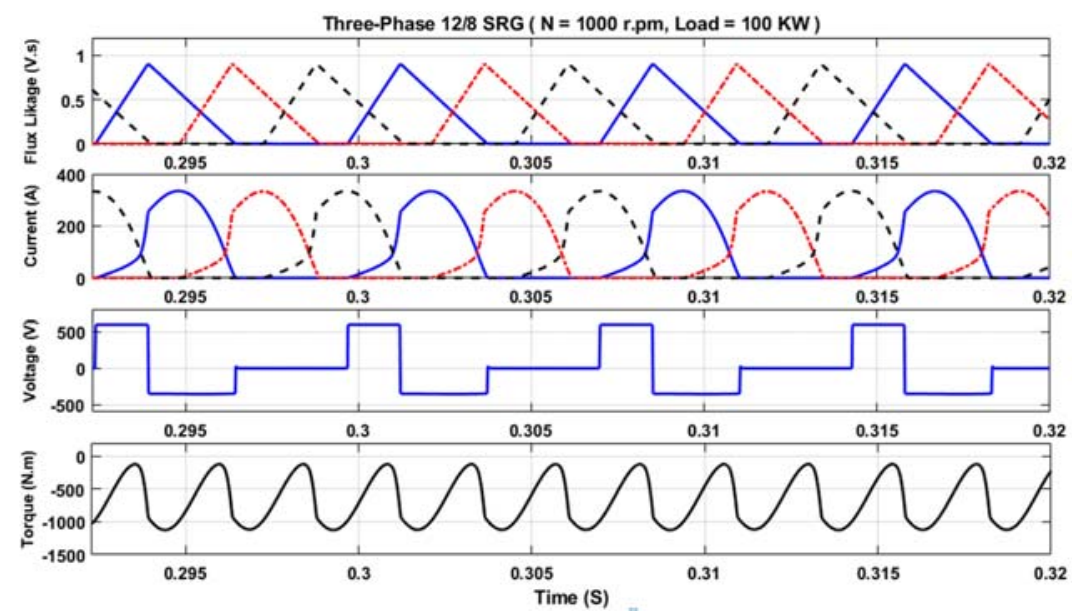

Figure 5. SRG flux, current, voltage and torque waveforms at $\alpha=-7 \mathrm{o}, \beta=9.5$ oand a constant load 
The performance of the $12 / 8 \mathrm{SRG}$ for rotor speed of $1000 \mathrm{rpm}$ with $\alpha=-7^{\circ}, \beta=9.5^{\circ}$ at a constant load of $100 \mathrm{~kW}$ is illustrated in Table 2 .

Table 2. Performance of SRG under loading conditions

\begin{tabular}{|c|c|}
\hline Results & $\alpha=-7^{\circ}, \beta=9.5^{\circ}$ \\
\hline RMS phase current $\mathrm{I}_{\mathrm{rms}}(\mathrm{A})$ & 173.1 \\
\hline Average phase current $\mathrm{I}_{\text {avg }}(\mathrm{A})$ & 112.3 \\
\hline DC bus output Voltage $V_{o}(\mathrm{~V})$ & 350 \\
\hline DC bus output Current $\mathrm{I}_{\mathrm{dc}}(\mathrm{A})$ & 286.5 \\
\hline Output power $\mathrm{P}_{\text {out }}(\mathrm{kW})$ & 100.2 \\
\hline Electromagnetic Torque (N.m) & 950 \\
\hline
\end{tabular}

\section{CLOSED LOOP OPERATION OF SRG}

A control technique is designed for the closed-loop operation required to control the voltage produced. The magnetization period width of the SRG phase varies according to this approach, Maintaining the value of $\theta_{\text {on }}$ fixed $\left(-7^{0}\right)$ and controlling the value of the $\theta_{\text {off }}$ through PI controller. If the speed of wind turbine or the loads varies, the value of $\theta_{\text {off }}$ will be changes by the PI controller [ 7, 16, 17 ]. As a control strategy in the production process, the PI controller is commonly used. Basically, The response speed, the steady-state error and system performance are enhanced by the PI controller. Nevertheless, the PI parameter setting is referred to as system process characteristics. The PI controller's transfer function is.

$$
G c(S)=K p+\frac{K i}{S}
$$

The Integral of Time-Multiplied Square Error (ITSE) is used in this paper to evaluate and design the proposed controller for the performance index, and it's as given [18].

$$
\operatorname{ITSE}=\int_{0}^{\infty} t[e(t)]^{2} d t
$$

The PI controller will be tuned off line using both of PSO, WOA and GOA as presented in Figure 6.

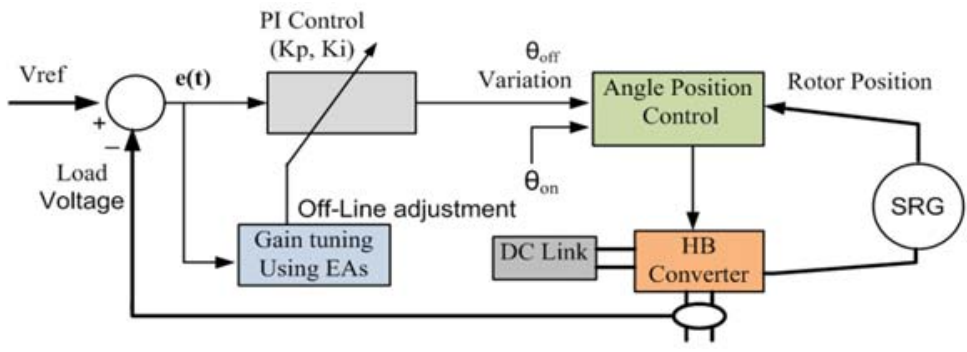

Figure 6. Structure of SRG voltage controller using PI with evolutionary tuning

\section{MODELLING OF PSO, WOA AND GOA}

\subsection{Particle swarm optimization (PSO)}

The PSO-PI controller is recommended in this section. PSO will study the method of tuning PI controller parameters. As the following equation, the operating algorithm is based on the best local and global solution $[18,19]$.

$$
v_{i}^{k+1}=w_{i} v_{i}^{k}+C_{1} \operatorname{rand} x\left(\text { Pbest }_{i}-S_{i}^{k}\right)+C_{2} \operatorname{rand}\left(\text { gbest }-S_{i}^{k}\right)
$$

where, $v_{i}^{k}$ at $k$ iteration is the velocity of particle $i, v_{i}^{k+1}$ is the particle $i$ updated velocity, $w_{i}$ is the weight and different inertia of particle $i, C_{1}$ and $C_{2}$ are constants of positive acceleration, $S_{i}^{k}$ at iteration $k$ is current position of particle $i$, rand is between 0 and 1 random number, $P$ best $t_{i}$ is the $i^{\text {th }}$ particle's best previous position, and gbest is the best particle in the population among all particles. The new position can, therefore, be modified with the present position and updated velocity as [19, 20]

Int J Pow Elec \& Dri Syst Vol. 11, No. 1, Mar 2020 : $75-85$ 


$$
S_{i}^{k+1}=S_{i}^{k}+v_{i}^{k+1}
$$

The constants positive acceleration $\mathrm{C}_{1}$ and $\mathrm{C}_{2}$ are set to 1.6. The weighted inertia $\mathrm{w}_{\mathrm{i}}$ is set within the range $(0.4$ to 0.9$)$.

\subsection{Whale optimization algorithm (WOA)}

In 2016, Mirjalili and lewis developed an optimization technique that is inspired by the whales' behavior, so-called WOA [21, 22]. Whales are presented as smart and quick animals in finding a prey. A whale firstly searches the prey, encircles it and then, by a strategy attacks the prey, called bubble-net hunting.

WOA assumes that a position is the best solution for a prey and then tries to change their positions towards this agent by the other research agents. Like all heuristic-based algorithms, WO simulates the behavior of swarm exploration and exploitation. In the beginning of the algorithm, the optimum design position is not known in the search space, the initial search agent is expected to be the target prey or close the optimum one. The other search agents attempt to change the positions towards the best one when the best search agency is determined. The best agent is described below:

$$
\begin{aligned}
& \vec{X}(t+1)=\vec{X}_{P}(t)-\vec{A} \cdot \vec{D} \\
& \vec{D}=\left|\vec{C} \cdot \vec{X}_{P}(t)-\vec{X}(t)\right|
\end{aligned}
$$

Where $\vec{X}_{P}$ and $\vec{X}$ stand for best solution of position and the whale current position, respectively, and $t$ indicates the number of current iteration. The vectors $\vec{A}$ and $\vec{C}$ are given by equation (17) in terms of a random vector $\vec{r}$ in $[0,1]$ and a shrinking bubbles vector $(\vec{a})$ which is decreased linearly from 2 to 0 , as expressed in (18).

$$
\begin{aligned}
& \vec{A}=2 \vec{a} \cdot \vec{r}-\vec{a} ; \vec{C}=2 \cdot \vec{r} \\
& \vec{a}=2-2 \frac{t}{t_{\max }}
\end{aligned}
$$

The bubble net hunting is also called the spiral system and has a different mechanism, because the humpback will travel to the prey in the form of a helix. The spiral motion is expressed in $\mathrm{Eq}(19)$

$$
\vec{X}(t+1)=\overrightarrow{D^{\prime}} \cdot e^{b l} \cdot \cos (2 \pi l)+\vec{X}_{P}(t)
$$

Where $\overrightarrow{D^{\prime}}=\left|\vec{X}_{P}(t)-\vec{X}(t)\right|$ and the distance between the prey and the $i$ th whale is determined, $b$ is the logarithmic spiral constant, and $l$ in $[-1,1]$ is a random number. The developers of WO assumed that probability $(\rho)$ determines the movement type, so any value of $\rho<0.5$ means that shrinking mechanism applies. Then, the spiral mechanism applies in case of $\rho \geq 0.5$. This allows WO to conduct a global search. Additionally. Readers may refer to WO for more information. [21].

\subsection{Grasshopper optimization algorithm (GOA)}

GOA is a newly proposed single target, a population-based heuristic algorithm that emulates grasshopper swarms ' behavior in nature and models them mathematically to optimization problems with litigating variables [12]. Among Grasshoppers, the algorithm simulates repulsion and attraction forces. While forces of repulsion allow grasshopper to search space, forces of attraction urge them to exploit promising regions. So that the exploration is balanced and extraction process, GOA was provided with a coefficient decreasing the grasshoppers comfort zone. This allows GOA not to get trapped in local ultimate and find a reliable global optimum calculation. Because the best solution the swarm has achieved so far is regarded as a chased objective, the grasshoppers have a strong opportunity of finding the global optimum through the improvement of the target over the course of the iterations [23, 24]. The GOA equation of position update is given by

$$
X_{i}^{d}=r\left(\sum_{\substack{j=1 \\ j \neq i}}^{N} r \frac{u b_{d}-l b_{d}}{2} S\left(\left|X_{j}^{d}-X_{i}^{d}\right|\right) \frac{X_{j}-X_{i}}{d_{i j}}\right)+T_{d}
$$

Where, $X_{i}^{d}$ is the position in $d$-th dimension the current solution, $r$ is a coefficient of diminishing, which narrows the area of comfort, repulsion and attraction zone, $u b_{d}$ in $d$-th dimension upper bound, $l b_{d}$ in

Voltage control of switched reluctance generator using grasshopper optimization algorithm (M. Bahy) 
$d$-th dimension lower bound, $S$ describes the social forces among grasshoppers, $d_{i j}$ shall be absolute value for the distance among $j$-th grasshopper $X_{j}$ and $i$-th grasshopper $X_{i}$ and $T_{d}$ in $d$-th value of dimension target, which solution has been found to date. Eq (20) shows that a grasshopper's next position depends on his position current, all other grasshopper's position, and the target position. in Eq (20) the function of social forces is defined as

$$
S=f e^{\frac{-d}{l}}-e^{-d}
$$

While, $f$ indicates the attraction strength and $l$ is length scale of attractive. In proportion to the iterations number to balance of exploration and exploitation, parameter $r$ in Eq (20) should be reduced. It facilitates the use as the increasing number of iterations. It also reduces the comfort zone according to the iterations number and is measured accordingly [25]

$$
r=r_{\max }-t \frac{r_{\max }-r_{\min }}{T}
$$

Wherever $r_{\max }$ is the value of maximum, $r_{\min }$ is the value of minimum, $t$ is the current iteration, and $T$ is the number of iterations maximum. In this paper $r_{\max }$ and $r_{\min }$ is 1 and 0.00001 respectively.

\section{SIMULATION RESULTS}

\subsection{System response with PI controller tuned by PSO, WOL and GOA}

To maintain the output voltage of the SRG at $350 \mathrm{~V}$, for the output checking of the controller parameters PSO-PI according to the evaluation, the parameters of PSO are used as follows:

- $\quad$ Size of population $=25$;

$-\quad w_{\max }=0.9, w_{\min }=0.1$

$-\quad C_{1}=C_{2}=1.6$

- Iteration $=60$;

For the WOA, there are only two control parameters; $\vec{a}$ which was directly reduced from 2 to 0 and the random vector $\vec{r}$ in $[0,1]$. The best results were obtained using the typical values, Iteration $=60$

To verify the Performance of the GOA-PI controller parameters, the following parameters of GOA are used:

- Number of search agents $=25$

- Number of iterations $=60$

Figure 7. shows the convergence curves of the WOA, PSO, and GOA algorithms. It can be clearly seen that GOA converges to the global value faster than the other algorithms for the problem under consideration. By heuristic tuning methods for the tuned and optimized PI controller, the parameters obtained after the simulation process are illustrated in Table 3.

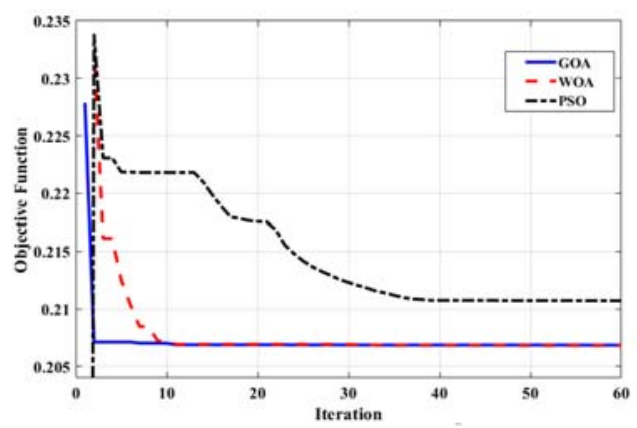

Figure 7. The fitness function versus number of iterationa

Table 3. Parameters of optimized PI

\begin{tabular}{lll}
\hline Controller Type & $K_{p}$ & $K_{i}$ \\
\hline PSO_PI & 0.0231 & 2.0121 \\
WOA_PI & 0.0985 & 2.9537 \\
GOA_PI & 0.0665 & 2.745 \\
\hline
\end{tabular}

Int J Pow Elec \& Dri Syst Vol. 11, No. 1, Mar 2020 : 75 - 85 
As shown in Figure 8(a), the proposed controller can hold the voltage generated at the rated value of $350 \mathrm{~V}$. Figure 8(b) shows the power supplied to the load. The performance features that define the transient response of a unit step input are maximum overshoot, settling time, rise time and steady state error. Thus, the implications of these features are shown in Table 4. The performance of the proposed GOA-PI controller in comparison with other controllers is verified for these effects.

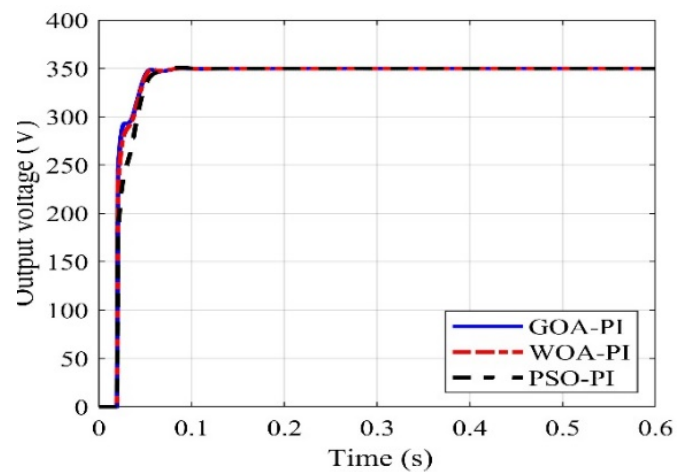

(a) System output voltage

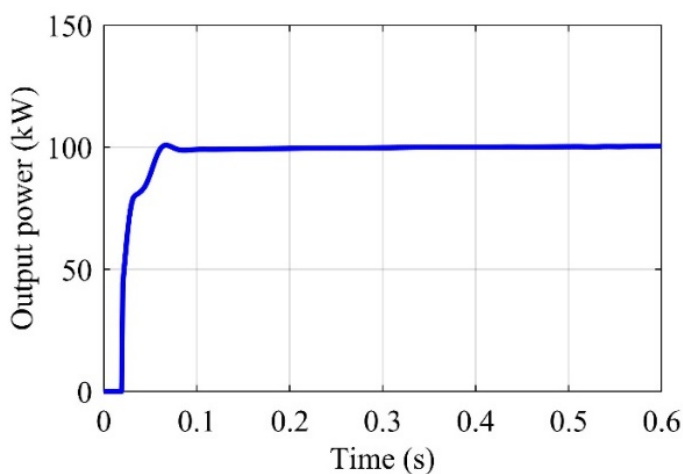

(b) System output power

Figure 8. Step response of the system with PI controller tuned by PSO, WOA and GOA

Table 4. Results of the system for transient response analysis.

\begin{tabular}{cccccc}
\hline Controller Type & Overshot $\%$ & Settling Time $(\mathrm{sec})$ & Rising Time $(\mathrm{sec})$ & Peak Time $(\mathrm{sec})$ & ITSE value \\
\hline PSO_PI & 0.258 & 0.0569 & 0.0249 & 0.0919 & 0.2107 \\
WOA_PI & 0.2388 & 0.0508 & 0.022 & 0.0895 & 0.20686 \\
GOA_PI & 0.238 & 0.0506 & 0.0214 & 0.0869 & 0.2068 \\
\hline
\end{tabular}

GOA-PI has better results than PSO-PI for maximum overshoot by $7.75 \%$ and $0.335 \%$ compared to WOA-PI. For settling time, GOA-PI has better results by $11.07 \%$ compared to PSO-PI and $0.394 \%$ compared to WOA-PI. For rise time, GOA-PI has better results by $14.056 \%$ compared to PSO-PI, $2.73 \%$ compared to WOA-PI. For peak time, GOA-PI has better results by $5.44 \%$ compared to PSO-PI and $1.822 \%$ compared to WOA-PI. In the same Table 4 are also indicated the performance index values for different controllers. The proposed controller gives minimum of ITSE value in comparing with the other controllers, as seen in this table. This results confirm that the GOA tuned controller has better performance than the other PSO and WOA tuned controllers.

\subsection{Testing of the proposed controller}

To clarify the robustness of the suggested controller, two scenarios will be occurred in the load at 0.3 second. In Figure 9, the load is decreased suddenly from $100 \mathrm{~kW}$ to $58 \mathrm{~kW}$. Furthermore, the load is increased suddenly from $64 \mathrm{~kW}$ to $100 \mathrm{~kW}$, as shown in Figure 10.

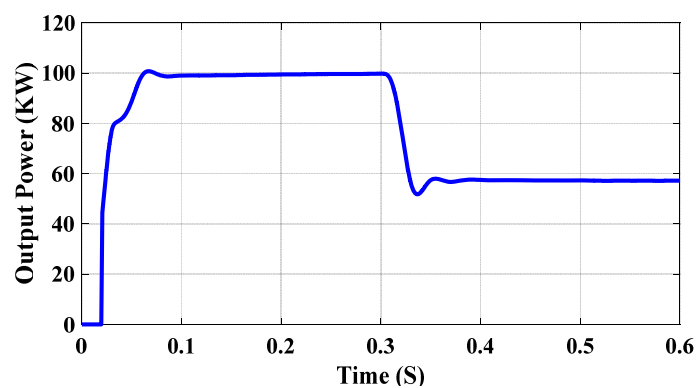

Figure 9. SRG output power as the load decreases

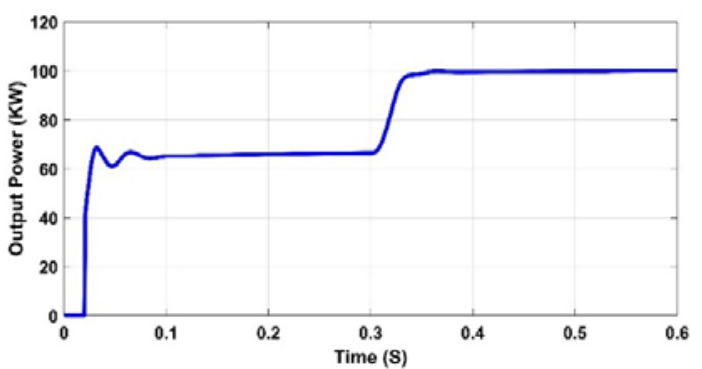

Figure 10. SRG output power as the load increases 
The system voltage response with optimum PI controller tuned by GOA, WOA and PSO techniques using ITSE fitness function are shown in Figures 11 and 12. Due to the load variation, the SRG terminal voltage is enhanced closely to $350 \mathrm{~V}$ with small overshoot and recovery time. The results obtained verify the effectiveness of the GOA-based voltage control system.

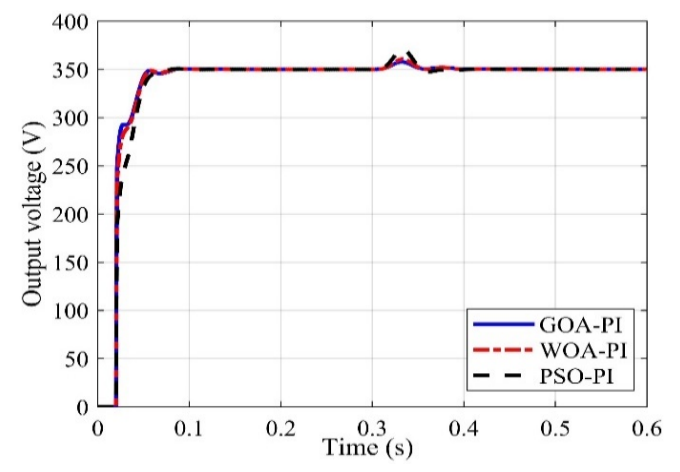

Figure 11. The output voltage response using (ITSE) for decreasing the load

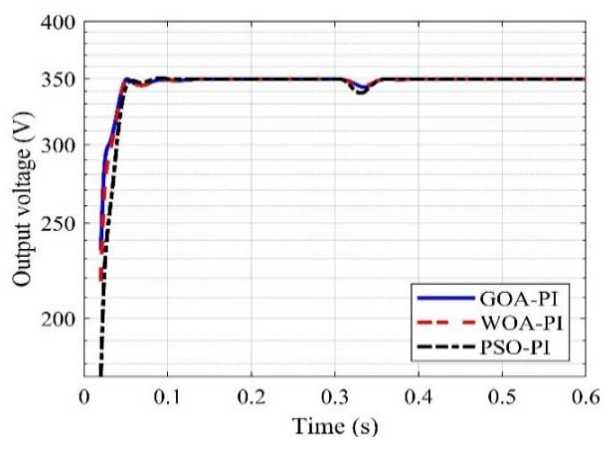

Figure 12. The output voltage response using (ITSE) for increasing the load

In addition, the changing of the wind speed is decreased from $12 \mathrm{~m} / \mathrm{s}$ to $10 \mathrm{~m} / \mathrm{s}$ at 0.4 second as illustrated in Figure 13. During this event, the terminal voltage of the SRG terminal voltage is regulated closely to $350 \mathrm{~V}$ with small overshoot and recovery time. Also, it is revealed that the system voltage response with optimum PI controller tuned by GOA, WOA and PSO techniques using ITSE fitness function, as shown in Figure 14. The results obtained verify the effectiveness of the proposed GOA based controller for voltage control system.

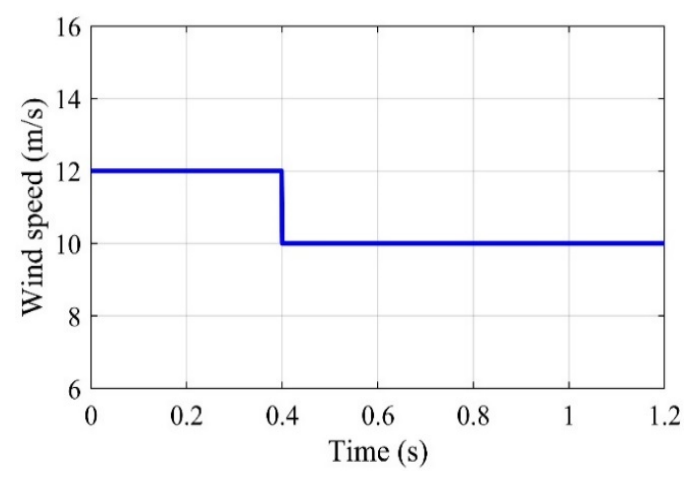

Figure 13. Step change in the wind speed

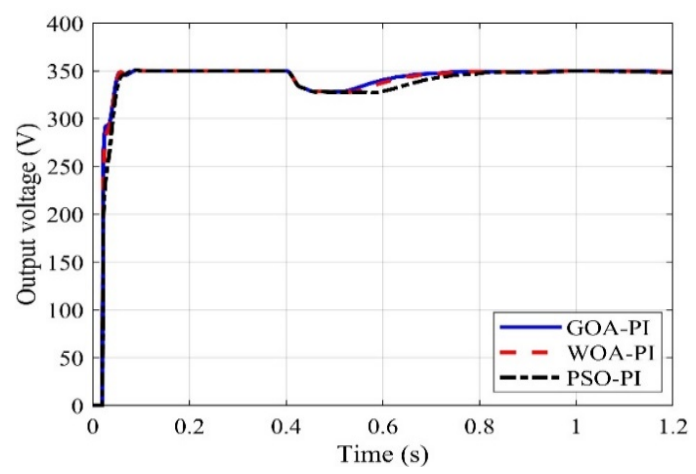

Figure 14. The output voltage response using (ITSE) for increasing the load

\section{CONCLUSION}

This paper presents output voltage control of SRG based on wind turbine of $100 \mathrm{KW}$ with electric grid using a PI controller tuned by both GOA, WOA and PSO. For the parameter tuning technique, the control principle is to direct the switches of the electrical converter, to provide optimal parameters for the ITSE-based PI controller, the GOA algorithm is frequently used. The controller is tested in three cases, increases the load, decreases load and changes in wind speed. The simulation results show that the proposed GOA-PI controller can find optimum controller parameters quickly and efficiently. The GOA-PI controller is also compared with the WOA-PI and PSO-PI controllers using the results of transient analyses and validity analysis. The results of simulation using a GOA-PI controller for SRG based wind turbine show better performance of voltage control than the other tuning methods.

Int J Pow Elec \& Dri Syst Vol. 11, No. 1, Mar 2020: $75-85$ 


\section{REFERENCES}

[1] C. R. D. Osorio, R. P. Vieira, and H. A. Grundling, "Sliding mode technique applied to output voltage control of the switched reluctance generator," in IECON Proceedings (Industrial Electronics Conference), 2016.

[2] J. L. Beniwal and R. K. Tripathi, "A novel four-phase active boost switched reluctance inverter for high speed SRM drive," International Journal of Power Electronics and Drive Systems, vol 8, no 4, pp. 1562-1574 2017.

[3] M. N and M. C, "Implementation of PI Controller for 4ф Srm Drive Using TMS320F28335," International Journal of Power Electronics and Drive System (IJPEDS), vol. 5, no. 3, p. 283, 2017.

[4] S. Yan, Q. Wang, H. Chen, and D. Yu, "Switched reluctance generator control for wind power system," in IEEE International Conference on Power Electronics, Drives and Energy Systems, PEDES 2016, 2017.

[5] K. W. Hu, J. C. Wang, T. S. Lin, and C. M. Liaw, "A switched-reluctance generator with interleaved interface DCDC converter," IEEE Trans. Energy Convers., vol. 30, no. 1, pp. 273-284, 2015.

[6] T. A. D. S. Barros, P. J. D. S. Neto, P. S. N. Filho, A. B. Moreira, and E. R. Filho, "An approach for switched reluctance generator in a wind generation system with a wide range of operation speed," IEEE Trans. Power Electron., 2017.

[7] G. P. Viajante et al., "A grid connection scheme of a switched reluctance generator using P+Resonant controller," in Conference Proceedings - 2017 17th IEEE International Conference on Environment and Electrical Engineering and 2017 1st IEEE Industrial and Commercial Power Systems Europe, EEEIC / I and CPS Europe 2017, 2017.

[8] E. S. Lopes Oliveira, M. L. Aguiar, and I. Nunes Da Silva, "Strategy to control the terminal voltage of a SRG based on the excitation voltage," IEEE Lat. Am. Trans., vol. 13, no. 4, pp. 975-981, 2015.

[9] J. G. Ziegler and N. B. Nichols, "Optimun setting for automatic controllers," Trans. Am. Soc. Mech. Eng., 1942.

[10] B. Hekimoğlu and S. Ekinci, "Grasshopper optimization algorithm for automatic voltage regulator system," in 2018 5th International Conference on Electrical and Electronics Engineering, ICEEE 2018, 2018.

[11] I. Luthra, S. K. Chaturvedi, D. Upadhyay, and R. Gupta, "Comparative study on nature inspired algorithms for optimization problem," in Proceedings of the International Conference on Electronics, Communication and Aerospace Technology, ICECA 2017, 2017.

[12] S. Saremi, S. Mirjalili, and A. Lewis, "Grasshopper Optimisation Algorithm: Theory and application," Adv. Eng. Softw., vol. 105, pp. 30-47, 2017.

[13] M. R. C. Reis, W. P. Calixto, W. R. H. Araujo, and C. A. Matias, "Increasing efficiency of the switched reluctance generator using parametric regression and optimization methods," in Proceedings of the 2017 18th International Scientific Conference on Electric Power Engineering, EPE 2017, 2017.

[14] N. Fernandes, R. Bindu, and S. George, "Control of switched reluctance generator in wind energy system," in Proceedings of 2016 Online International Conference on Green Engineering and Technologies, IC-GET 2016, 2017.

[15] N. Farah, M. H. N. Talib, J. Lazi, M. A. Ali, and Z. Ibrahim, "Multilevel inverter fed switched reluctance motors (SRMs) 6/4, 8/6 and 10/8 SRM geometric types," International Journal of Power Electronics and Drive System (IJPEDS), vol. 8, no. 2, pp. 584-592, Jan. 2017.

[16] G. P. Viajante, D. A. Andrade, L. C. Gomes, M. A. A. Freitas, V. R. Bernardeli, and A. W. F. V. Silveira, "A voltage control strategy for Switched Reluctance Generator," in Proceedings of the 2013 IEEE International Electric Machines and Drives Conference, IEMDC 2013, 2013.

[17] A. W.F.V. Silveira, D. A. Andrade, A. Fleury, L.C. Gomes, C. A. BissochiJr, H.de Paula "Generated Voltage Control In A Switched Reluctance Motor/Generator," in Eletrônica de Potência Campinas, vol. 15, no.3, pp. 203-212, 2010.

[18] R. R. Nasyrov, R. I. Aljendy, and A. A. Z. Diab, "Adaptive PI controller of active power filter for compensation of harmonics and voltage fluctuation based on particle swarm optimization (PSO)," in Proceedings of the 2018 IEEE Conference of Russian Young Researchers in Electrical and Electronic Engineering, ElConRus 2018, 2018.

[19] M. Sihem, B. Amar, and B. Hocine, "Optimal design of Switched Reluctance Motor using PSO based FEM-EMC modeling," Int. J. Electr. Comput. Eng., 2015.

[20] A. A. Z. Diab, S. A. Selim, and B. E. Elnaghi, "Particle swarm optimization based vector control of permanent magnet synchronous motor drive," in Proceedings of the 2016 IEEE North West Russia Section Young Researchers in Electrical and Electronic Engineering Conference, EIConRusNW 2016, 2016.

[21] S. Mirjalili and A. Lewis, "The Whale Optimization Algorithm," Adv. Eng. Softw., 2016.

[22] S. Raj and B. Bhattacharyya, "Optimal placement of TCSC and SVC for reactive power planning using Whale optimization algorithm," Swarm Evol. Comput, 2018.

[23] Mirjalili SZ, Mirjalili S, Saremi S, Faris H, Aljarah I., "Grasshopper optimization algorithm for multi-objective optimization problems," Appl Intell, 2018.

[24] Hekimoğlu B, Ekinci S., "Grasshopper optimization algorithm for automatic voltage regulator system," 20185 th Int Conf Electr Electron Eng, pp. 152-6, 2018.

[25] A. I. Omar, S. H. E. Abdel Aleem, E. E. A. El-Zahab, M. Algablawy, and Z. M. Ali, "An improved approach for robust control of dynamic voltage restorer and power quality enhancement using grasshopper optimization algorithm," ISA Trans., 2019. 